\title{
Bacillus megaterium: a Potential and an Efficient Bio- Degrader of Polystyrene
}

\author{
Tan Kian Meng \\ https://orcid.org/0000-0002-8185-1370
}

Angzzas Sari Binti Mohd Kassim

https://orcid.org/0000-0002-7519-0019

\author{
Aliff Hisyam Bin A Razak \\ https://orcid.org/0000-0003-1438-0510
}

Noor Akhmazillah Binti Mohd Fauzi*
https://orcid.org/0000-0002-5108-7914

Universiti Tun Hussein Onn Malaysia, Faculty of Engineering Technology, Department of Chemical Engineering Technology, Pagoh Education Hub, Panchor, Johor, Malaysia.

Editor-in-Chief: Paulo Vitor Farago

Associate Editor: Ana Cláudia Barana

Received: 2019.05.22; Accepted: 2020.08.09.

${ }^{*}$ Correspondence: akhma@uthm.edu.my; Tel.: +6-06-9742041 (N.A.B.M.F.).

\section{HIGHLIGHTS}

- Bacillus megaterium strain was first reported contributed in polystyrene biodegradation.

- Viability of Bacillus megaterium utilizing polystyrene was confirmed by TTC reduction test.

- FESEM showed localized degradation on PS-film surrounding the bacterial cells in the biofilm.

- FTIR showed changes in chemical structure of the PS-film.

\begin{abstract}
This research has been conducted to investigate the biodegradation of polystyrene (PS) by isolated strain Bacillus megaterium from Zophobas morio's. The viability and metabolic activity of Bacillus megaterium utilizing emulsified PS in liquid carbon free basal medium as sole carbon source was confirmed using redox probe 2,3,5-triphenyltetrazolium chloride (TTC). Bacillus megaterium showed prominent result with TTC, which forms red colored insoluble TPF (triphenyl formazan) within four to seven days. The formation of TPF confirmed the metabolism activity of the cell using PS as source of carbon. The biodegradation activity of Bacillus megaterium on PS film was also confirmed by FTIR analysis, the result showed changes in functional groups due to microbial activities. FESEM analysis was carried out on the PS surface, revealing the formation of bacterial biofilm as well as occurrence of porosity and fragility of the bacterial deteriorate surface compared to control. Overall, the identification of plastic degrading bacteria (PDB) will become a fundamental platform promoting more in-depth research for optimal plastic waste management to switch from the conventional landfilling to enzymatic biodegradation. In the long run, it is to regulate the current global plastic waste accumulation on Earth which poses potent ecological threat.
\end{abstract}


Keywords: Bacillus megaterium; biodegradation; biofilm; polystyrene.

\section{INTRODUCTION}

Recently, the global usage of petroleum-based synthetic plastics has increased yearly. Expanded polystyrene (EPS) foam, commonly known as Styrofoam, is one of the main products of PS has displayed a yearly worldwide production approximately 21 million tons in 2013 [1]. Generally, EPS is considered as a safe material that complies with respect to necessary technical and environmental standards. However, EPS contributes to 'white pollution'- one of the major marine pollutions [2]. Majority of the PS products can be recycled, however, process of recovery of these wastes are often more expensive than virgin plastic. Besides, transporting the big volume residues of low-density PS to recycling is costly and economically unfeasible. Hence, there are number of industry issues arise concerning eco-efficiency, availability, corporate social responsibility, product quality or hygiene aspects, and traceability of the recycled PS products. Disposal of these products has created environmental pollution due to their chemical stability which causing them inert to biodegradation [3]. Increasing landfill costs and decreasing landfill space are forcing consideration of alternative options for the disposal of polystyrene materials. Apparently, PS alone has silted up one-third of the world's landfills, it is rather urgent to look for a green and cost-effective alternative for PS degradation.

In the current work, the authors have successfully isolated the PS-degrading strain and identified as Bacillus megaterium strain based on 16S rRNA sequencing aligned with Gen Bank database using Basic Local Alignment Search Tool (BLAST) and the data is in the process of publication. With reference to previous literatures, it has been reported Bacillus megaterium strain which inhabited in the oil contaminated sites was believed to be capable to metabolize both n-alkanes and aromatic hydrocarbons in petroleum [4,5]. The ability of Bacillus megaterium in degrading petroleum has been widely applied in solving environmental problems such as biodegradation of oily sludge and crude oil removal [4,6,7], diesel degradation [8] and bioremediation of lubricant oil pollution in water [9].

In addition to biodegradation of aromatic compounds, it has been reported that Bacillus megaterium is a lignin peroxidase producing bacteria which indicated its potential in lignin degradation [10]. Besides, it has also stated that Bacillus megaterium strain NOB showed good growth when cultured on lignocellulosic substrates and utilized $90-100 \%$ of lignin-related aromatic compounds [11]. It has also been reported Bacillus megaterium SBS3 for its biodegradation potential on both phenol and benzene [12]. For polymer degradation, Bacillus megaterium strain is used in the biodegradation of low density polyethylene (LDPE) [13]. This bacterium also has large potential in degradation process for biodegradable natural rubber latex film [14].

Information about this strain seems to be scarce, with almost no references to Bacillus megaterium on its PS-degrading potential. Nevertheless, research studies discussed above offer a new insight of this strain in degrading aromatic compounds which found also in PS. Petroleum hydrocarbons-degrading potential of Bacillus megaterium strain open an opportunity to the biodegradation of this petroleum-based plastic. In response to the lack of studies on its wider abilities and characteristics, this study aims to characterize its PS biodegradation ability and suggest new applications for this strain. This is the first report on the biodegradation potential of Bacillus megaterium on PS.

\section{MATERIAL AND METHODS}

\section{Polystyrene (PS)}

The Styrofoam feedstock tested for biodegradation was collected as recycle waste from a local electrical appliances shop in Parit Raja, Batu Pahat, Johor, Malaysia.

\section{Liquid carbon free basal medium (LCFBM)}

Liquid carbon free basal medium was used as the enrichment medium for PS-degrading microorganisms. It was prepared by dissolving $0.7 \mathrm{gL}^{-1}$ dipotassium phosphate $\left(\mathrm{K}_{2} \mathrm{HPO}_{4}\right), 0.7 \mathrm{gL}^{-1}$ potassium phosphate $\left(\mathrm{KH}_{2} \mathrm{PO}_{4}\right), 0.002 \mathrm{gL}^{-1}$ sodium chloride $(\mathrm{NaCl}) ; 0.005 \mathrm{gL}^{-1}$ ammonium nitrate $\left(\mathrm{NH}_{4} \mathrm{NO}_{3}\right), 1.0 \mathrm{gL}^{-1}$ magnesium sulphate $\left(\mathrm{MgSO}_{4} \cdot 7 \mathrm{H}_{2} \mathrm{O}\right) ; 0.001 \mathrm{gL}^{-1}$ zinc sulphate $\left(\mathrm{ZnSO}_{4} \cdot \mathrm{H}_{2} \mathrm{O}\right) ; 0.001 \mathrm{gL}^{-1}$ manganate sulphate $\left(\mathrm{MnSO}_{4} \cdot \mathrm{H}_{2} \mathrm{O}\right) ; 0.002 \mathrm{gL}^{-1}$ ferum sulphate, $\left(\mathrm{FeSO}_{4} \cdot 7 \mathrm{H}_{2} \mathrm{O}\right)$ in deionized water compliance to the American Society for Testing and Materials (ASTM) standard for studying the bacteria resistance to plastics (ASTM G22-76) [15]. 


\section{Preparation of PS emulsion and PS film}

Preparation of PS emulsion for microbial degradation was done according to the methods described by Nishida and Tokiwa [16] with some modifications. $100 \mathrm{~mL}$ of $3 \%$ Styrofoam in dichloromethane was transferred to $250 \mathrm{~mL}$ of amber bottle containing $100 \mathrm{~mL}$ LCFBM kept at $4^{\circ} \mathrm{C}$ for 2 days. After 2 days, the PS emulsion was placed in a fume hood overnight to volatilize the dichloromethane solvent [17]. For PS film, 10 $\mathrm{mL}$ of $3 \%$ Styrofoam in dichloromethane was spread on the glass petri dish. After 5 hours, the formed films were taken off and fixed in a hood at room temperature for 3 days. The films were then rinsed with methanol solvent, followed by deionized water, and dried again before use [18].

\section{Isolation and identification of PS degrading bacteria}

The PS-degrading bacteria was isolated from the midgut of Zophobas morio (Superworm) after feeding solely on PS diet for two weeks. The culture enrichment was prepared in LCFBM and PS emulsion as the sole carbon source, incubated at ambient temperature for 30 days. Isolation of single colonies of interest was facilitated by using modified PS-agar plate. DNA of the colonies was extracted using DNA extraction kit provided by First Base Laboratories Sdn. Bhd., Malaysia. Extracted DNA material was undergone PCR amplification prior to $16 \mathrm{~S}$ rRNA sequencing. The 16S rRNA sequences obtained were analysed via Basic Local Alignment Search Tool (BLAST). The partial 16S rRNA sequence compared with the top ten BLAST database entries revealed the isolate achieve $99 \%$ similar characteristic with the sequence of Bacillus megaterium strain.

\section{Primary screening of isolates viability and metabolic activity}

The ability of Bacillus megaterium utilizing polystyrene as sole source of carbon and energy was examined using indicator redox probe 2,3,5-triphenyltetrazolium chloride (TTC). Glucose was added as the carbon source in positive control medium whereas, non-inoculum sample culture served as negative control. The degradation activity was investigated by adding aliquot of $20 \mu \mathrm{L}$ of TTC (1\%) to $5 \mathrm{~mL}$ of culture medium as an indicator for cell viability [19]. Growth of the bacteria can be confirmed when the colorless TTC medium is being reduced to red-colored triphenyl formazan (TPF) as a results of bacteria electron transport chain enzyme activity.

\section{Quantification of biofilm formed on PS-film via total protein content estimation}

Protein quantification is a quick, commonly available assay which allows for a relative assessment of biofilm growth by assuming that protein content is correlate with the number of cells in biofilms. Colonized PS-film samples were removed from the LCFBM at regular time intervals of 3 days and boiled for 30 minutes in $3 \mathrm{~mL}$ of $0.5 \mathrm{M}$ sodium hydroxide [20]. The suspension was centrifuged at $10000 \mathrm{~g}$ for 15 minutes. The supernatant was removed and the protein content was quantified via Bradford's assay using BSA as standard protein assays [21,22].

\section{Biodegradation characterizations}

\section{FESEM-Evaluation of PS film surface structure}

Bacillus megaterium inoculum of 24 hour- old culture were inoculated into $250 \mathrm{~mL}$ of LCFBM containing surface sterilized PS films $(1 \times 1 \mathrm{~cm})$ as sole source of carbon incubated at $37^{\circ} \mathrm{C}$ and $120 \mathrm{rpm}$ with fermentation duration of 14 and 30 days [23]. After the incubation period, the recovered PS film was cleaned with $2 \%$ SDS solution then rinsed with distilled water several time and left for air dried. FESEM analysis (JOEL, JSM 7600F, Japan) was carried out on the PS film surface to investigate the bacterial biomass biofilm and morphological surface attrition. A thin layer of gold was coated on the PS film surface using $5 \mathrm{kV}$ of accelerating voltage for 30 seconds to conduct electricity under nitrogen atmosphere [24,25]. Software Image $\mathrm{J}$ was used to measure the areas of the biofilm formed for both 14 and 30 days old culture [26].

\section{FTIR-Evaluation of PS-film chemical structure}

PS films sized $(1 \times 1 \mathrm{~cm})$ were analyzed using a Perkin Elmer infrared spectrometer (Spectrum 2000, Shelton, CT) combined with attenuated total reflectance (ATR) technique at the wavelength number range from 4000 to $450 \mathrm{~cm}^{-1}$. Each sample was recorded with 16 scans at a resolution of $4 \mathrm{~cm}^{-1}$ for detection of the 
formation of new functional groups or deviation of existing functional groups [27]. Aromatic $\mathrm{C}-\mathrm{H}$ stretching vibration at ranges of $3000 \mathrm{~cm}^{-1}$ and $1600 \mathrm{~cm}^{-1}$ whereas aromatic $\mathrm{C}-\mathrm{H}$ deformation vibration at ranges 1200 $\mathrm{cm}^{-1}$ and $700 \mathrm{~cm}^{-1}$ and $\mathrm{C}-\mathrm{H}$ bending at $1340 \mathrm{~cm}^{-1}$ were evaluated. The FTIR chromatograph obtained for degraded PS-film was compared with control non-degraded PS-film [28].

\section{RESULTS}

\section{Viability and metabolic activity Bacillus megaterium}

Viability experiment was carried out along with positive (mineral medium + glucose + isolate) and negative (mineral medium + PS emulsion) as controls. The results showed that the colourless TTC was readily reduced to red-coloured triphenyl formazan (TPF) by the bacterial electron transport system (ETS) with positive-control-glucose, sample after one day of incubation. Whereas, for PS added sample, the medium started to turn red after four days of incubation (Figure 1).

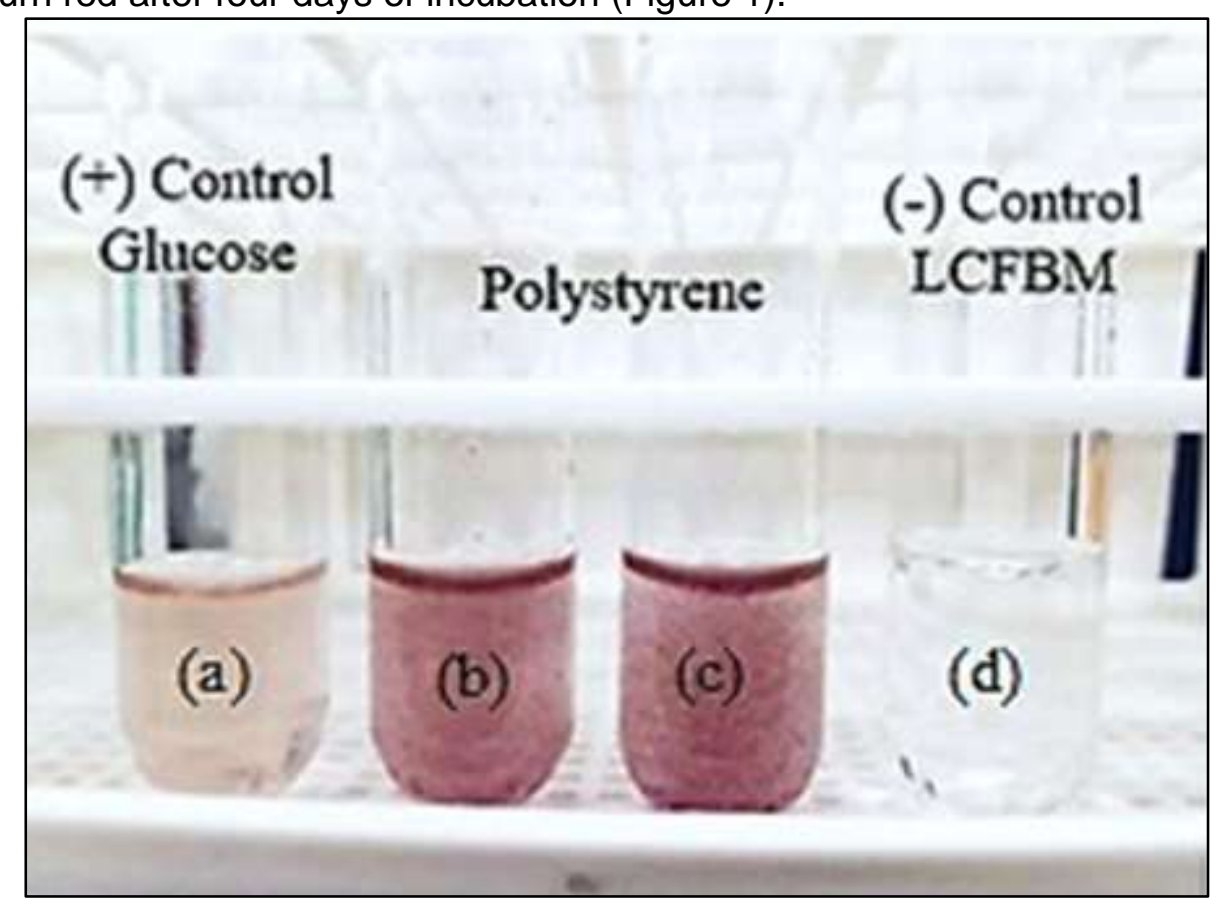

Figure 1. The metabolic activity of Bacillus megaterium measured by the reduction of TTC to TPF: (a) positive control glucose added, (b) and (c) duplicated samples of emulsified PS as sole carbon source and (d) negative control without inoculum.

\section{Total protein content estimation of biofilm}

After an early lag phase of two days, the protein content increased sharply on the third day and the amount was at peak of $91.1 \mu \mathrm{g}$ protein $\mathrm{cm}^{-2}$ on fourth and fifth days indicating cell adhesion to the film. It decreased sharply to minimal value of $46.4 \mu \mathrm{g}$ protein $\mathrm{cm}^{-2}$ after a week of incubation. This bacterial biomass showed a gradual increase of protein content after ten days of incubation (Figure 2). Although the bacterial growth was relatively slow, it proceeded in a sustainable manner as gradual increase of protein content observed as the incubation period prolonged. 


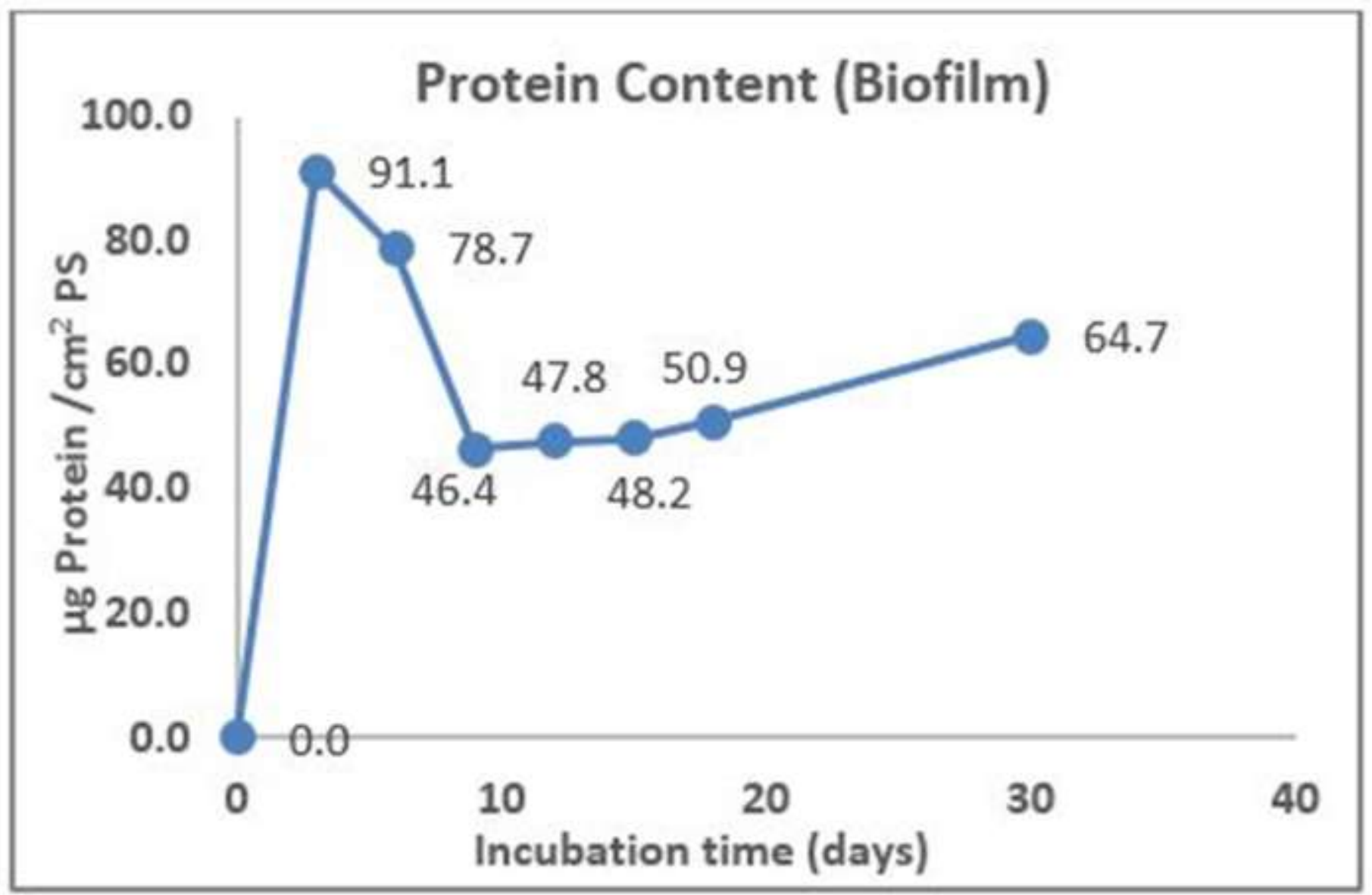

Figure 2. Protein content of bacterial biomass in biofilm colonizing the PS-film surface.

\section{Evaluation of PS-film surface structure}

Representative FESEM photomicrographs of 14 and 30 days old biofilm under magnification power of 50,000 indicating degradation was occurred, as presented in Figure 3 a and b. PS-film without treatment with Bacillus megaterium had a flat and smooth surface, treated PS-films showed bacteria colonies adhered on the surface and formed biofilm. Surface cracks and voids indicating degradation. Similar findings were previously reported for other plastic polymers such as HIPS film [20] and Poly (3-hydroxybutyrate-co-3hydroxyvalerate) [29].

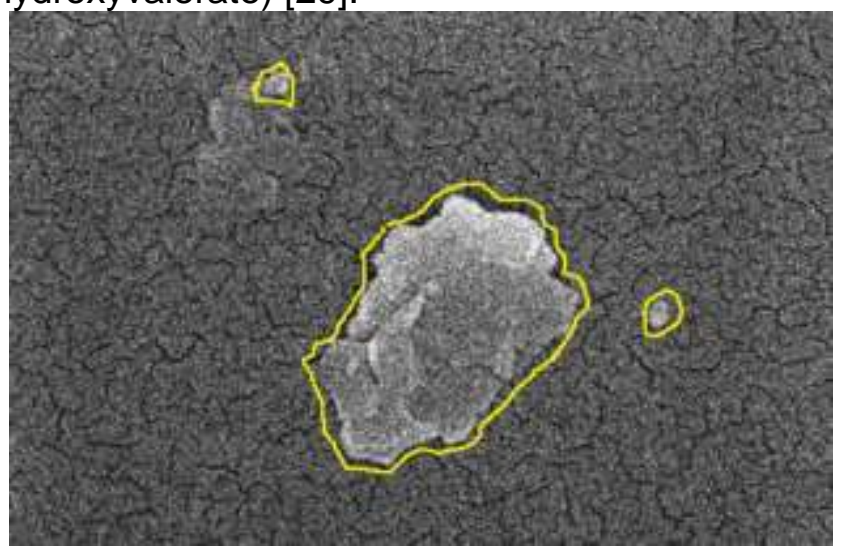

(a)

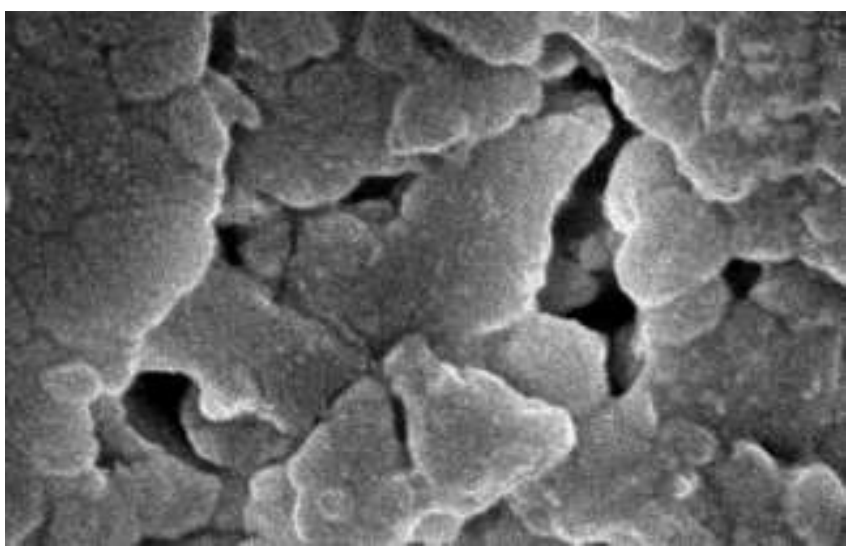

(b)

Figure 3. FESEM images of biomass on treated PS film after incubation with Bacillus megaterium for (a) 14 days and (b) 30 days at magnification of 50,000 .

Biofilm formation showed a proliferation trend that aligned to the curve of total protein content estimation of biofilm as shown in Figure 3. Interestingly, it can be observed the biofilms in $\mathbf{3 0}$ days old culture has 
covered nearly the entire surface area of PS-film $\left(4.23 \times 10^{6} \mathrm{~nm}^{2}\right)$ whereas for 14 days old culture, only about $18 \%$ of the surface covered by biofilms (selected in yellow). Apparently, the cells density in biofilm proliferates with time.

Moreover, it can be observed that PS film was damaged and more extensively voids on PS film surface were observed in 30 days old culture than in 14 days culture as shown in Figure 4 a and Figure $4 \mathrm{~b}$ respectively. The damaged areas were highlighted in yellow. Based on the analysis data, the percentage of surface corrosion found in 30 days old culture $(1.5 \%)$ was double the one found in 14 days old culture $(0.64 \%)$. The corroded areas were calculated based on the size of the pits proportion to the total surface area of PSfilm.

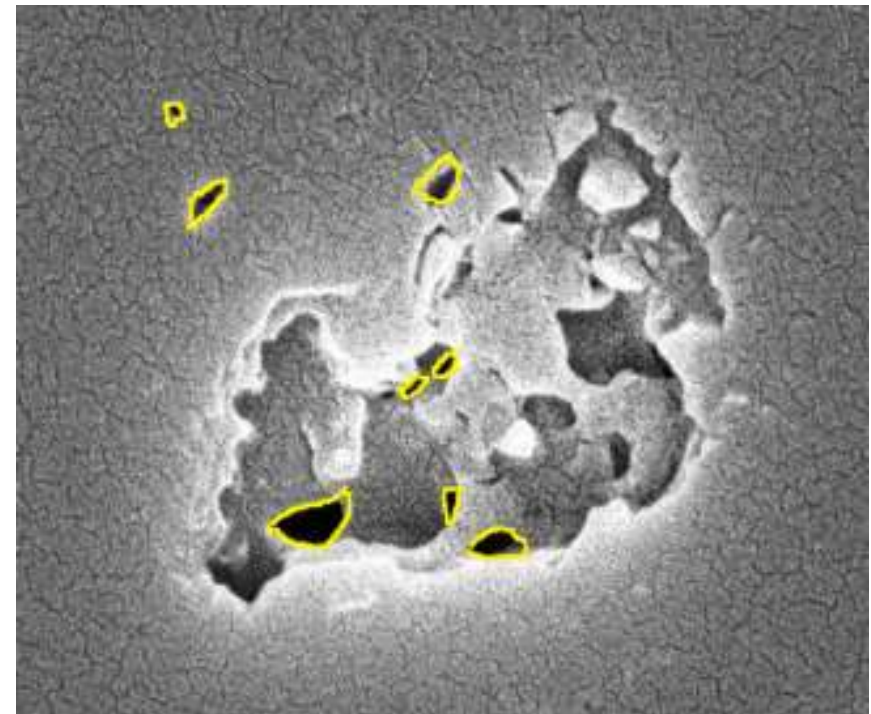

(a)

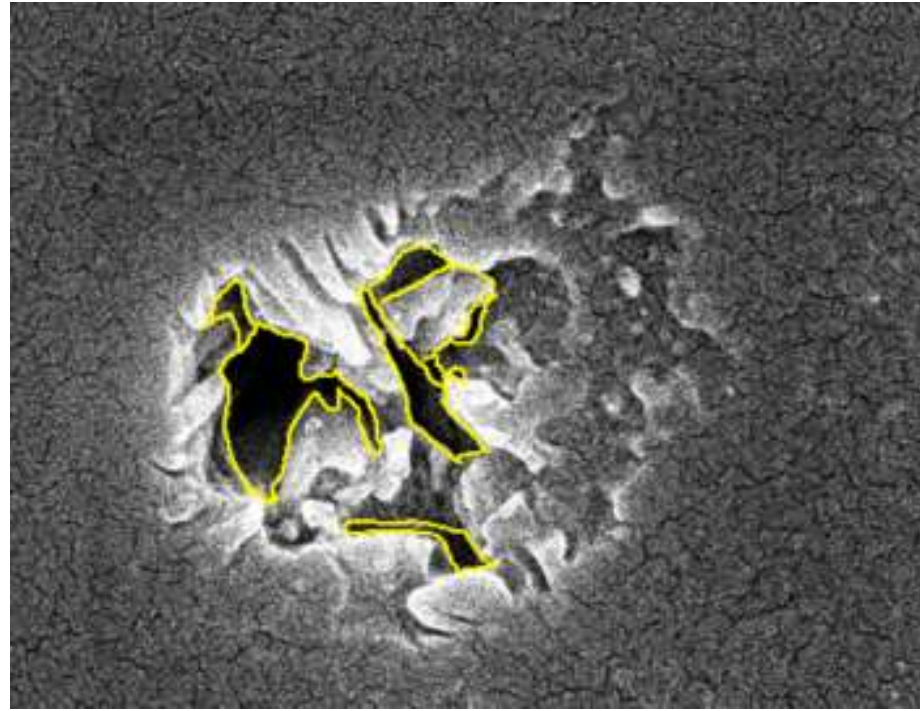

(b)

Figure 4. FESEM images of surface morphological changes on treated PS film after incubation with Bacillus megaterium for (a) 14 days and (b) 30 days at magnification of 50,000.

\section{Evaluation of PS-film chemical structure}

The FTIR spectrum of PS-film (Figure 5) showed the typical aromatic peak at ranged $696 \mathrm{~cm}^{-1}, 748 \mathrm{~cm}^{-1}$, $1452 \mathrm{~cm}^{-1}, 1492 \mathrm{~cm}^{-1}, 1600 \mathrm{~cm}^{-1}$ and $3025 \mathrm{~cm}^{-1}$. After 30 days incubation of PS-film with Bacillus megaterium, there was a marked reduction of the intensity of aromatic residues. The peaks at $3025 \mathrm{~cm}^{-1}$ correspond to aromatic $\mathrm{C}-\mathrm{H}$ stretching, and $1602 \mathrm{~cm}^{-1}$ corresponding $\mathrm{C}-\mathrm{C}$ aromatic ring stretch respectively. The peak at $748 \mathrm{~cm}^{-1}$ corresponds to out-of-plane $\mathrm{C}-\mathrm{H}$ bending mode of the aromatic ring. Also, the peak at $696 \mathrm{~cm}^{-1}$ represent to ring-bending vibration. The peaks correspond to benzene ring found at $1492 \mathrm{~cm}^{-1}$ and $1600 \mathrm{~cm}^{-1}$. The treated PS-films presented maximum increased in transmittance (reduced in absorbance) in FTIR spectra signifying biodegradation such as $748 \mathrm{~cm}^{-1}$ (mono substituted aromatic compound), $1027 \mathrm{~cm}^{-1}$, $1450 \mathrm{~cm}^{-1}, 1492 \mathrm{~cm}^{-1}$ ( $\mathrm{C}=\mathrm{C}$ stretching vibration of aromatic ring), $1602 \mathrm{~cm}^{-1}(\mathrm{C}=\mathrm{C}$ stretching vibrations in the aromatic ring), $2921 \mathrm{~cm}^{-1}$ (C-H alkyl stretch) [30-32]. 

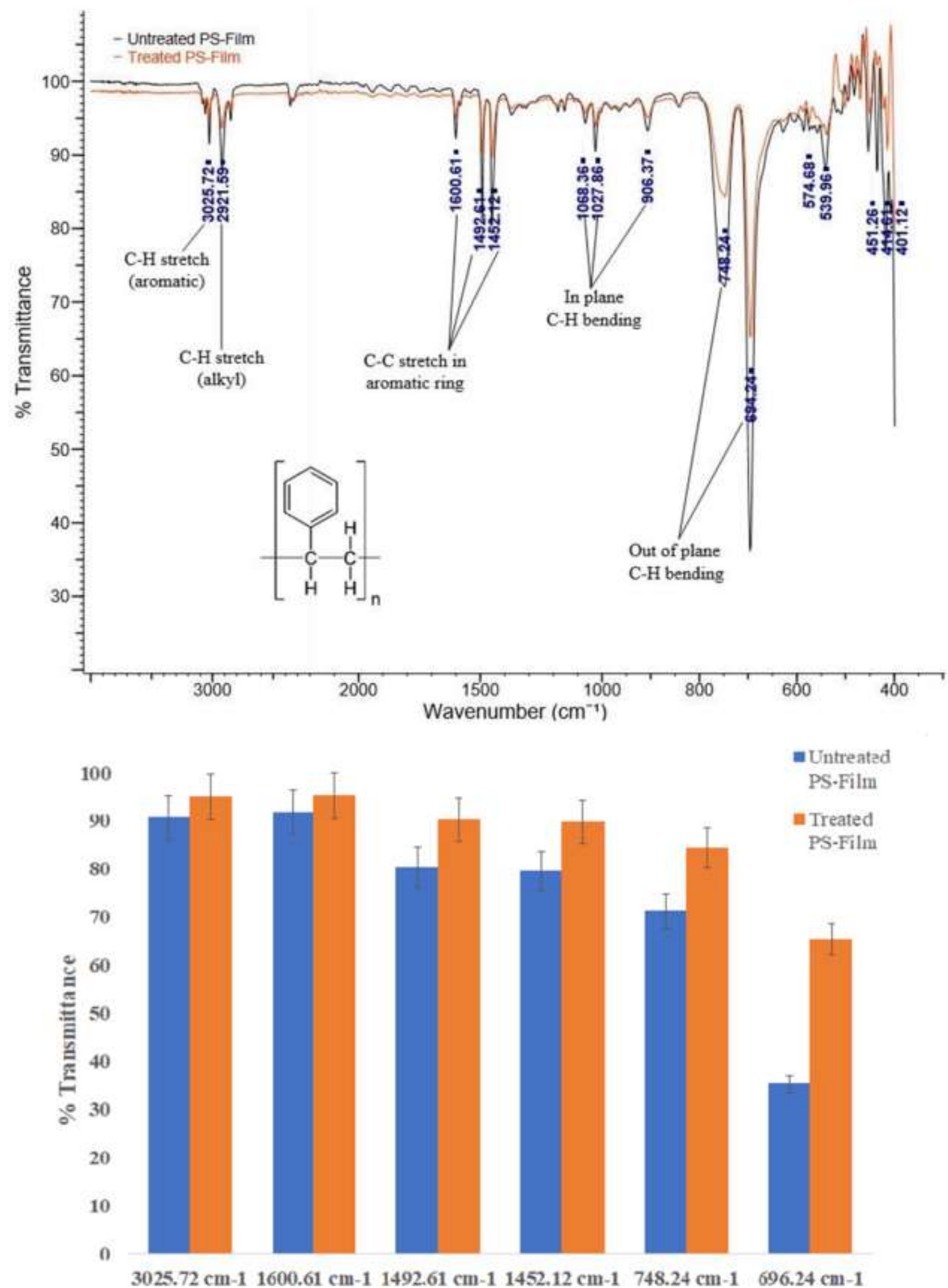

\section{Wavenumber}

Figure 5. FTIR spectrum and the ratio of the targeted group for the of control untreated PS-film and biodegraded treated PS-film after 30 days incubation. 


\section{DISCUSSION}

In this research, TTC reduction test was applied as it is a quick and effective method for verifying the viability of PS-degrading bacteria. Preliminarily, the viability was found on PS emulsion prepared in LCFBM as sole source of carbon within four to seven days of incubation and the cell activity was detected as the colorless medium culture turned red as TTC reduced to TPF. As incubation period prolonged, the red colour changed darker and stopped after 14 days of incubation. Formation of TPF suggested Bacillus megaterium utilized the polystyrene as carbon source during their metabolism activity. This can be postulated that TTC was functioned as artificial electron acceptors which replace oxidizing agent (oxygen) as the final $\mathrm{H}^{+} / \mathrm{e}^{-}$ acceptor and was reduced by the aerobic cytochrome system to form water-insoluble, red-colored formazans by microbial enzymatic activities [33,34]. The difference in the red colour intensity between glucose added sample and PS was determined by the amount of vital cells presence in the medium. More vital cells resulted in a darker red colour [35]. It is also noted that the bacteria's metabolism activity began to slow down once the limited simple form of carbon source ( $2 \%$ glucose) has been utilised completely. Whereas, PS, a more complex polymer required a longer time to be broken down into short chain monomers that can be readily permeate through the cell wall and utilised by bacteria as carbon source to growth [36]. The bacterial growth in both control and experimental samples were soon terminated by the accumulation of metabolic inhibitors in the medium. Hence, the results obtained clearly demonstrated that the survivability and growth of the isolate Bacillus megaterium were taken place when polystyrene was present as a sole carbon source.

Currently, there is no uniform gold standard for biofilm quantification for different surfaces and established biofilms. Protein quantification can be a good approach to determine the formation of biofilm resulted from the bacterial adhesion to PS-film. Analysis of protein content of the biofilm indirectly reflects the density of biomass and colonization rate of Bacillus megaterium on PS-film [37,38]. Initially, there was a sharp decline in protein content as presented in Figure 3 which indicating the fast proliferating population of Bacillus megaterium which attached to PS-film surface at initial stage of incubation utilized the organic substances (eg. bacteria metabolites) as a carbon source. The quick cell multiplication can be explained with a simple equation $\mathrm{m} 2^{\mathrm{n}}$, where $\mathrm{m}$ represents the starting population number and $\mathrm{n}$ is the generation number under a wide range of environmental conditions [39].

Employing carbon starvation at which the PS film was the sole source of carbon present in the medium apparently resulted in cell death due to PS is non-organic carbon source to the organisms, as could be seen in the simultaneous decrease in biomass. However, because of their survival strategy and crude oil degrading potentiality give advantage to cells adapting slowly to the environment and adhering on the petroleum base plastic (PS film). The protein content increased gradually after ten days of incubation resulting from a proliferating biofilm developed slowly and steadily on the PS film as the sole source of carbon [40]. Formation of biofilm on the plastic surface plays an vital role in biodegradation which favors the plastic degrading bacteria to grow [41] and enable them to assimilate carbon source from PS film.

Polyethylene and PS are the common example of hydrophobic plastic polymers. It has been proposed that strains have more hydrophobic surfaces can play a crucial role in promoting colonization of the polymer in the early stage $[42,43]$ prior to formation of a stable biofilm. Indeed, Sakharovski and coauthors revealed that carbon starvation is correlated to bacterial hydrophobicity [44]. In addition, Sivan and coauthor claimed carbon starvation induced changes in bacterial surface hydrophobicity [45]. It was revealed that carbon starvation promotes hydrophobicity as a result carbon starved bacteria cells became more hydrophobic and more adhesive than non-starved cells. Similarly, recent study on formation of biofilm on polyethylene by Rhodococcus ruber showed high viability and adherent of the polyethylene surface without supplementation of any external carbon up to 60 days of incubation [46]. All the evidences above eventually give an explanation to constantly increase in the protein ten days and prolonged incubation.

Overall, above these findings give a deeper insight to the high affinity of Bacillus megaterium cells for PS. Low carbon availability in Bacillus megaterium strain cultures possibly enhances hydrophobic interactions and proliferation of biofilm. Nevertheless, microbial biofilm quantification appears to have drawbacks in lacking direct and reliable methods for quantifying the biomass of the biofilm. Hereby we applied an established qualitative analysis using FESEM to check the morphological changes on PS film surface in order to confirm the presence of bacterial biomass. Both quantitative and qualitative results showed positive correlation which the FESEM images taken showed an increase of bacterial biomass as an adherent community on the PS-film for 30 days old culture (Figure $3 \mathrm{~b}$ ).

FESEM photomicrographs captured for evaluation of PS-film surface structure showed some localized degradation of the PS surrounding the bacterial cells in the biofilm. Above results evinced to the positive 
correlation between biofilms density and morphological changes induced on PS-film. This could be attributed to the increase in cell density in biofilms that utilized the PS film as the sole source of carbon for cell growth. The evidences presented suggest that the biofilm formed at initial stage prior to biodegradation of PS-film which resulted in morphological damage with time as illustrated in Figure 6. In early stage, selected strain Bacillus megaterium present, attached and colonize the PS-film surface in the form of biofilms. Attached microbes initiate hydrophobic interactions upon its contact with the polymer surface. Plastic was adsorbed by inorganic ions (basal medium containing $\mathrm{K}, \mathrm{Na}$ and $\mathrm{Ca}$ ) and molecules which promotes microbial attachment. As the time passes, the degradation of leaching components such as additives and monomers or oligomers took place providing a food source to the bacteria strain. The enzymatic attack leads breakage of polymer chains and loss of mechanical stability. However, microbial filaments delve deep inside the polymer synthesizes biosurfactants and accumulate water for further hydrolysis, which also leads to increased conductivity. Lipophilic pigments are released assisting to discoloration of the plastic. Surface morphological changes such voids, pit holes and cracks were observed indicating biodegradation activity of the bacteria strain [47-49].

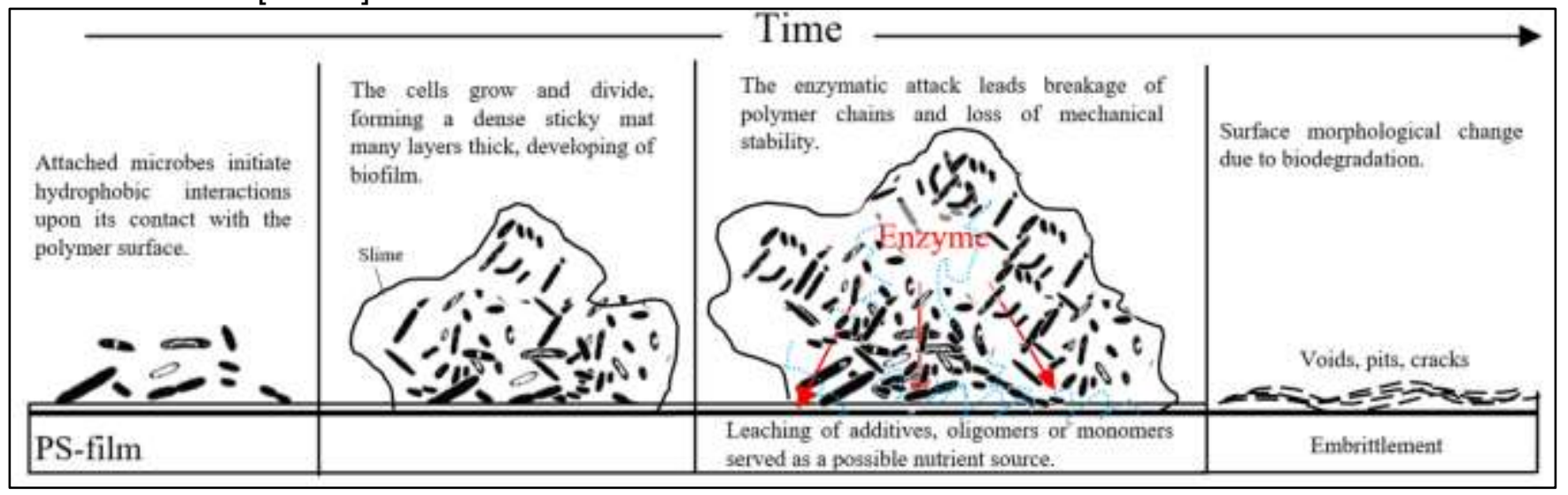

Figure 6. Stages and effects of biofilm on PS-film surface.

FTIR analysis was applied to examine the interactions between the macromolecules and changes in chemical structure of the PS-film after incubation with Bacillus megaterium. Referring to literature, $2924 \mathrm{~cm}^{-}$ 1 and $2852 \mathrm{~cm}^{-1}\left(\mathrm{CH}_{2}\right.$ asymmetric and symmetric stretches), $3026 \mathrm{~cm}^{-1}$ (aromatic C-H stretches), $756 \mathrm{~cm}^{-1}$ (out-of-plane $\mathrm{C}-\mathrm{H}$ bends mode of the aromatic ring), $698 \mathrm{~cm}^{-1}$ (ring-bending vibration) and $1600 \mathrm{~cm}^{-1}$ and $1491 \mathrm{~cm}^{-1}$ (benzene ring) are the key absorbance peaks that representing polystyrene [28,50]. Chemical structure of PS consists of an aromatic benzene ring which is making it hard to biodegrade [51]. However, after incubation with Bacillus megaterium, the PS-related peaks at 1600, 1492, 748 and $696 \mathrm{~cm}^{-1}$ wave numbers (reduced in absorbance) and reduced in the peak intensity, suggesting there were bond weakening possibly had been taken place in PS [52].

\section{CONCLUSION}

For the first time, this present study reports on the potential of newly isolated strain Bacillus megaterium from Zophobas morio's gut for the biodegradation of PS. The biodegradation of PS film was corroborated by FTIR analysis and showed alteration in functional groups because of microbial activities. FESEM analysis confirmed the degradation of PS by revealing the biofilm formed on the PS-film surface as well as the presence of porosity and brittleness of the bacterial degraded surface compared to control. Besides, FESEM analysis also revealed that Bacillus megaterium can modify and colonize PS as the source of carbon eventually established the important role played by the selected strain in PS biodegradation process. The discovery of bacteria strain used PS as a sole carbon and energy source emerging a significant interest of study in enzymatic biodegradation mechanism on recalcitrance of PS. This finding unwraps the possibility to utilize enzyme to tackle environmentally relevant non-biodegradable polymer accumulation. However, this research performed mainly based on descriptive nature, with a few relevant studies devoted to polystyrene degradation. These findings are limited, further evidences are required to elucidate the complete mechanisms for polystyrene degradation. A synergetic bioprocess using Bacillus megaterium with a consortium selected microbe to treat PS waste in our environment and extraction of targeted PS-degrading enzyme from Bacillus 
megaterium strain to give a deep insight on enzymatic degradation could be a promising work to be done in future.

Funding: This research was funded by Postgraduate Research Grants Universiti Tun Hussein Onn Malaysia (UTHM), grant number GPPS U769.

Acknowledgements: Authors gratefully appreciate to laboratory representatives from Department of Chemical Engineering Technology, Faculty of Engineering Technology i.e. Mohd Redzuan Mohd Nor, Masayu Maslan and Aziah Abu Samah for their helps and technical supports in this project.

Conflicts of interest: The authors declare no conflict of interest. The funders had no role in the design of the study; in the collection, analyses, or interpretation of data; in the writing of the manuscript, or in the decision to publish the results

\section{REFERENCES}

1. Plastics Europe. Plastics - The Facts 2013: An analysis of European latest plastics production, demand and waste data [Internet]. Belgium: PlasticEurope; 2013 [Cited on 13 May 2018]. Available from: http://www. plasticseurope.org/Document/plastics-the-facts 2013.aspx?Page=DOCUMENT\&FollD=2.

2. Botelho G, Queiros A, Machado A, Frangiosa P, Ferreira, J. Enhancement of the thermooxidative degradability of polystyrene by chemical modification. Polym. Degrad. Stab. 2004;86:493-7.

3. Arvanitoyannis I, Biliaderis, CG. Physical properties of polyol-plasticized edible blends made of methyl cellulose and soluble starch. Carbohydr. Polym. 1999;38:47-58.

4. Cerqueira VS, Hollenbach EB; Maboni F, Vainstein MH, Camargo FAO, Peralba M do CR, Bento FM. Biodegradation potential of oily sludge by pure and mixed bacterial cultures. Bioresour. Technol. 2011;102:1100310.

5. Yudono B, Said M, Sabaruddin, Napoleon A, Utami MB. Kinetics of petroleum contaminated soil biodegraded by an indigenous bacteria Bacillus megaterium. HAYATI J. Biosci. 2011;17:155-60.

6. Thavasi R, Jayalakshmi S, Banat IM. Effect of biosurfactant and fertilizer on biodegradation of crude oil by marine isolates of Bacillus megaterium, Corynebacterium kutscheri and Pseudomonas aeruginosa. Bioresour. Technol. 2011;102:772-8.

7. Riskuwa-shehu ML, ljah UJJ. Enhanced removal of crude oil in soil by mixed culture of Bacillus megaterium UL05 and Pseudomonas aeruginosa UL07. Int. J. Environ. Bioremediation Biodegrad. 2016;4:8-12.

8. Dixit $\mathrm{H}$, Lowry M, Mohsin U, Moond M, Kumar S. Screening and identification of diesel oil degrading bacterial isolates from petroleum contaminated soil of Barmer. J. Pharm. Chem. Biol. Sci. 2018;6:34-40.

9. Gopinath SM, Shareef MI, Ashalatha, Ganessin A. Bioremediation of lubricant oil pollution in water by Bacillus megaterium. Int. J. Innov. Res. Sci. Eng. Technol. 2015;4:6773-80.

10. Patil SR. Production and purification of lignin peroxidase from Bacillus megaterium and its application in bioremidation. CIBTech J. Microbiol. 2014;3:22-8.

11. Buraimoh $\mathrm{OM}$, llori $\mathrm{MO}$, Amund $\mathrm{OO}$. Characterization of lignocellulolytic bacterial strains associated with decomposing wood residues in the Lagos lagoon, Nigeria. Malays. J. Microbiol. 2015;11:273-83.

12. Vijayan D, Kochupurackal J, Abraham A, Chandrasekharan Nair I. Microbial consortia formulation for the effective biodegradation of benzene, toluene, xylene and phenol. J. Microbiol. Biotech. Food Sci. 2014;3:457-62.

13. Abrusci C, Pablos JL, Corrales T, Lopez-Marin J, Marín I, Catalina F. Biodegradation of photo-degraded mulching films based on polyethylenes and stearates of calcium and iron as pro-oxidant additives. Int. Biodeterior. Biodegrad. 2011;65:451-9.

14. Tajuddin ZM, Azura AR. Bacillus megaterium sp. as degradation agent for biodegradable natural rubber latex films. Adv. Mater. Res. 2013;626:813-7.

15. ASTM. International standard practice for determining resistance of plastics to bacteria. West Conshohocken, PA: ASTM International;1996.

16. Nishida $\mathrm{H}$, Tokiwa $\mathrm{Y}$. Distribution of poly ( $\beta$ - hydroxybutyrate) and poly ( $\varepsilon$-caprolactone) aerobic degrading microorganisms in different environments. Environ. Polym. 1993;1:227-33.

17. Shah AA, Eguchi T, Mayumi D, Kato S, Shintani N, Kamini NR, Nakajima-Kambe T. Purification and properties of novel aliphatic-aromatic co-polyesters degrading enzymes from newly isolated Roseateles depolymerans strain TB87. Polym. Degrad. Stab. 2013;98:609-18.

18. Yang Y, Yang J, Wu WM, Zhao J, Song Y, Gao L, Yang R, Jiang L. Biodegradation and mineralization of polystyrene by plastic-eating mealworms: Part 2 Role of gut microorganisms. Environ. Sci. Technol. 2015;49:12087-93. 
19. Sekhar VC, Nampoothiri KM, Mohan AJ, Nair NR, Bhaskar T, Pandey A. Microbial degradation of high impact polystyrene (HIPS), an e-plastic with decabromodiphenyl oxide and antimony trioxide. J. Hazard. Mater. 2016;318:347-54.

20. Mohan AJ, Sekhar VC, Bhaskar T, Nampoothiri KM. Microbial assisted High Impact Polystyrene (HIPS) degradation. Bioresour. Technol. 2016;213:204-7.

21. Grintzalis K, Georgiou CD, Schneider YJ. An accurate and sensitive Coomassie Brilliant Blue G-250-based assay for protein determination. Anal. Biochem. 2015;480:28-30.

22. Sedmak JJ, Grossberg SE. A rapid, sensitive, and versatile assay for protein using Coomassie brilliant blue G250. Anal. Biochem. 1977;79:544-52.

23. Jarerat A, Pranamuda H, Tokiwa Y. Poly (L-lactide) degrading activity in various Actinomycetes. Macromol. Biosci. 2002;2:420-8.

24. Chae DW, Kim BC. Characterization on polystyrene/zinc oxide nanocomposites prepared from solution mixing. Polym. Adv. Technol. 2005;16:846-50.

25. Dang TCH, Nguyen DT, Thai H, Nguyen TC, Hien Tran TT, Le VH, Nguyen VH, Tran XB, Thao Pham TP, Nguyen, TG. Plastic degradation by thermophilic Bacillus sp. BCBT21 isolated from composting agricultural residual in Vietnam. Adv. Nat. Sci. Nanosci. Nanotechnol. 2018;9.

26. Jensen EC. Quantitative analysis of histological staining and fluorescence using ImageJ. Anat. Rec. 2013;296:37881.

27. Milstein O, Gersonde R, Huttermann A, Frund R, Feine HJ, Ludermann HD, Chen MJ, Meister JJ. Infrared and nuclear magnetic resonance evidence of degradation in thermoplastics based on forest products. J. Environ. Polym. Degrad. 1994;2:137-52.

28. Allen NS, Barcelona A, Edge M, Wilkinson A, Galan C, Santa VR. Thermal and photooxidation of high styrene butadiene copolymer (SBC). Polym. Degrad. Stab. 2004;86:11-23.

29. Wang Z, Gao J, Li L, Jiang H. Purification and characterization of an extracellular poly(3-hydroxybutyrate-co-3hydroxyvalerate) depolymerase from Acidovorax sp. HB01. World J. Microbiol. Biotechnol. 2012;28:2395-2402.

30. Elashmawi IS, Hakeem NA, Abdelrazek EM. Spectroscopic and thermal studies of PS/PVAc blends. Phys. B Condens. Matter. 2008;403:3547-52.

31. Li J, Guo S, Li X. Degradation kinetics of polystyrene and EPDM melts under ultrasonic irradiation. Polym. Degrad. Stab. 2005;89:6-14.

32. Leroux F, Meddar L, Mailhot B, Morlat-Therias S, Gardette JL. Characterization and photooxidative behaviour of nanocomposites formed with polystyrene and LDHs organo-modified by monomer surfactant. Polymer. 2005;46:3571-8.

33. Alef K, Nannipieri P. Methods in applied soil microbiology and biochemistry.New York: Academic Press; 1995.

34. Schimmel SC, Morrison GE, Heber MA. Marine complex effluent toxicity program: Test sensitivity, repeatability and relevance to receiving water toxicity. Environ. Toxicol. Chem. 1989;8:739-46.

35. Moussa SH, Tayel AA, Al-Hassan AA, Farouk A. Tetrazolium/Formazan test as an efficient method to determine fungal chitosan antimicrobial activity. J. Mycol. 2013;2013:1-7.

36. Uttiya Dey UD. An approach to polymer degradation through microbes. IOSR J. Pharm. 2013;2:385-8.

37. Mor R, Sivan A. Biofilm formation and partial biodegradation of polystyrene by the actinomycete Rhodococcus ruber: Biodegradation of polystyrene. Biodegradation. 2008;19:851-8.

38. Hadad D, Geresh S, Sivan A. Biodegradation of polyethylene by the thermophilic bacterium Brevibacillus borstelensis. J. Appl. Microbiol. 2005;98:1093-1100.

39. Gu JD. Handbook of environmental degradation of materials: Microbial biofilms, fouling, corrosion, and biodeterioration of materials. $3^{\text {rd }} \mathrm{ed}$. [place unknown]: Elsevier Inc.; 2018.

40. Sivan A. New perspectives in plastic biodegradation. Curr. Opin. Biotechnol. 2011;22:422-6.

41. Lerchner J, Wolf A, Buchholz F, Mertens F, Neu TRR, Harms H, Maskow T. Miniaturized calorimetry: A new method for real-time biofilm activity analysis. J. Microbiol. Methods. 2008;74:74-81.

42. Tribedi P, Sil AK. Low-density polyethylene degradation by Pseudomonas sp. AKS2 biofilm. Environ. Sci. Pollut. Res. 2013;20:4146-53.

43. Gilan I, Hadar Y, Sivan A. Colonization, biofilm formation and biodegradation of polyethylene by a strain of Rhodococcus ruber. Appl. Microbiol. Biotechnol. 2004;65:97-104.

44. Sakharovski VV, Nikitin DL, Sakharovski VG. Physiological characterization of the survival of some gram negative bacteria under conditions of carbon deficiency. Appl Biochem Microbiol. 1999;35:430-1.

45. Sanin SL, Sanin FD, Bryers JD. Effect of starvation on the adhesive properties of xenobiotic degrading bacteria. Process Biochem. 2003;38:909-14. 
46. Sivan A, Szanto M, Pavlov V. Biofilm development of the polyethylene-degrading bacterium Rhodococcus ruber. Appl. Microbiol. Biotechnol. 2006;72:346-52.

47. Flemming HC. Relevance of biofilms for the biodeterioration of surfaces of polymeric materials. Polym. Degrad. Stab. 1998;59:309-15.

48. Shah AA, Nawaz A, Kanwal L, Hasan F, Khan S. Degradation of poly ( $\varepsilon$-caprolactone ) by a thermophilic bacterium Ralstonia sp . strain MRL-TL isolated from hot spring. Int. Biodeterior. Biodegrad. 2015; 98:35-42.

49. Janczak K, Hrynkiewicz K, Znajewska Z, Dąbrowska G. Use of rhizosphere microorganisms in the biodegradation of PLA and PET polymers in compost soil. Int. Biodeterior. Biodegrad. 2018;130:65-75.

50. Jang BN, Wilkie CA. The thermal degradation of polystyrene nanocomposite. Polymer. 2005;46:2933-42.

51. Singh B, Sharma N. Mechanistic implications of plastic degradation. Polym. Degrad. Stab. 2008;93:561-84.

52. Pushpadass HA, Weber RW, Dumais JJ, Hanna MA. Biodegradation characteristics of starch-polystyrene loose-fill foams in a composting medium. Bioresour. Technol. 2010;101:7258-64.

(C) 2021 by the authors. Submitted for possible open access publication under the terms and conditions of the Creative Commons Attribution (CC BY NC) license (https://creativecommons.org/licenses/by-nc/4.0/). 